TITLE:

\title{
Enhanced reduced model for elastic earthquake response analysis of a class of mono- symmetric shear building structures with constant eccentricity
}

\section{$\operatorname{AUTHOR}(\mathrm{S}):$}

Adachi, Fuyuki; Yoshitomi, Shinta; Tsuji, Masaaki; Takewaki, Izuru

\section{CITATION:}

Adachi, Fuyuki ...[et al]. Enhanced reduced model for elastic earthquake response analysis of a class of mono-symmetric shear building structures with constant eccentricity. Soil Dynamics and Earthquake Engineering 2011, 31(7): 1040-1050

\section{ISSUE DATE:}

2011-07

URL:

http://hdl.handle.net/2433/159443

\section{RIGHT:}

(C) 2011 Elsevier Ltd.; This is not the published version. Please cite only the published version.; この論文は出版社版でありません。引用の際に は出版社版をご確認ご利用ください。 


\title{
Enhanced reduced model for elastic earthquake response analysis of a class of mono-symmetric shear building structures with constant eccentricity
}

\author{
Fuyuki Adachi, Shinta Yoshitomi, Masaaki Tsuji and Izuru Takewaki ${ }^{\dagger}$ \\ Department of Architecture \& Architectural Engineering, Kyoto University, \\ Kyotodaigaku-katsura, Kyoto 615-8540, Japan
}

\begin{abstract}
An enhanced reduced model is proposed for elastic earthquake response analysis of a class of mono-symmetric shear building structures with constant eccentricity. The proposed reduction method consists of two parts. The first stage is the construction of a reduced structural model with the degrees of freedom at representative floor levels only. In this stage, an inverse eigenmode-problem formulation is used to guarantee the limited equivalence between the original model and the reduced model. The reduced model is constructed so as to have the same fundamental natural frequency and the same lowest-mode component ratios at the representative floor levels as those of the original model. The second stage is the transformation of earthquake input forces into a set of reduced input forces. This transformation utilizes the static equivalence of lateral-torsional stiffness between these two models and is introduced to enhance the accuracy level of the reduced model. Several examples of a three-dimensional mono-symmetric ten-story shear building model with constant eccentricity are presented to demonstrate the validity and accuracy of the proposed reduction method for earthquake response analysis.
\end{abstract}

Keywords: Lateral-torsional vibration, Earthquake response analysis, Reduced model, Inverse problem, Reduction of earthquake input, Eccentricity

${ }^{\dagger}$ Corresponding author, E-mail: takewaki@archi.kyoto-u.ac.jp, Tel: +81-75-383-3294, Fax: +81-75-383-3297 


\section{Introduction}

Lateral-torsional coupling in earthquake response of building structures with eccentricity is one of the key issues in the field of earthquake structural engineering (for example [1-16]). This is because such response has complicated properties and is difficult to tackle. Furthermore many earthquake damages have been reported for buildings with a fairly large eccentricity [17]. After a versatile research on this subject, some approaches have been introduced in the capacity spectrum method (for example [10]). For high-rise buildings with eccentricity, the allowable design response is within an elastic limit due to their importance and safety margin. In this case, a huge amount of computer resources is necessary to compute the earthquake response for many candidate ground motions [18]. Furthermore, when structural engineers seek an optimal or better design in terms of structural member sizes or passive damper locations, a versatile sensitivity analysis is required to obtain the redesign directions [19]. A time-history response analysis may be required to assure the accuracy and reliability of the response evaluation. To reduce these computational costs, a sophisticated reduced model is desired. Although some reduced models have been proposed, it is difficult to guarantee the accuracy for a wide range of structural and earthquake input parameters.

An enhanced reduced model is proposed in this paper for elastic earthquake response analysis of a class of mono-symmetric shear building structures with constant eccentricity. The proposed reduction method consists of two parts. The first stage is the construction of a reduced structural model with the degrees of freedom at representative floor levels only. In this stage, an inverse eigenmode-problem formulation [20-22] is used to guarantee the limited equivalence between the original model and the reduced model. More specifically, the reduced model is constructed so as to have the same fundamental natural frequency and the same lowest-mode component ratios at the representative floor levels as those of the original model. The second stage is the transformation of earthquake input forces into a set of reduced input forces. This transformation utilizes the static equivalence of lateral-torsional stiffness 
between these two models and is introduced to enhance the accuracy level of the reduced model.

Several reduction examples into one-mass and two-mass systems of a three-dimensional mono-symmetric ten-story shear building model with constant eccentricity throughout the stories are presented to demonstrate the validity and accuracy of the proposed reduction method for elastic earthquake response analysis. It is shown that the transformation of earthquake input forces into a set of reduced input forces is inevitable for accurate simulation of the earthquake response of the original model by the reduced structural model and the twomass system exhibits a higher accuracy than the one-mass system.

\section{Reduced model of building structures with eccentricity}

\subsection{Model description}

Consider a three-dimensional mono-symmetric shear building model as shown in Fig.1(a). The building floor plan is shown in Fig.1(b) and is assumed to be uniform throughout the stories. The center of mass is located at the central point and the center of rigidity of every floor exists at another common point. Let $e_{i}$ denote the distance between the center of mass and the center of rigidity in the $i$-th story. From the assumption stated before, $e_{i}=e$ for all $i$. The vibration in the $y$-direction does not include the lateral-torsional vibration and only the vibration in the $x$-direction exhibits the lateral-torsional vibration.

Let $k_{i}$ and $K_{i}$ denote the $x$-directional story stiffness and rotational stiffness around the center of rigidity, respectively, in the $i$-th story. The eccentricity ratio is defined by $R_{X i}=e_{i} / r_{X i}$ where $r_{X i}=\sqrt{K_{i} / k_{i}}$ is the radius of gyration of stiffness. The $y$-directional story stiffness in the $i$-th story is denoted by $\alpha k_{i}$ in terms of a prescribed parameter $\alpha$. Let $\mathbf{M}, \mathbf{K}$, C , $\omega^{(1)}$ and $h^{(1)}$ denote the mass matrix, the stiffness matrix, the damping matrix, the undamped fundamental natural circular frequency and the lowest-mode damping ratio of the shear building model in the $x$-directional lateral-torsional vibration. It is assumed that the damping matrix $\mathbf{C}$ is given by 


$$
\mathbf{C}=\frac{2 h^{(1)}}{\omega^{(1)}} \mathbf{K}
$$

\subsection{Structural model reduction based on inverse eigenmode-problem formulation}

While the reduction of the original structural system can be made into reduced models with any number of degrees of freedom, two examples of a one-mass system and a two-mass system are shown for simple and essential presentation of the proposed reduction method.

\subsubsection{Transformation into one-mass system}

Consider a one-mass system, as shown in Fig.1(a), with the same mass $\bar{m}_{1}$ and the mass moment of inertia $\bar{I}_{1}$ as the total mass and the total mass moment of inertia of the original shear building model. The reduced mass is located at the top floor. The center of mass of the one-mass system exists at the center of the floor and the center of rigidity is located at the same point as the original model, i.e. $\overline{e_{1}}=e$.

Let $\bar{k}_{1}, \bar{K}_{1}$ and $\bar{e}_{1}$ denote the $x$-directional story stiffness, the rotational stiffness around the center of rigidity and the distance between the center of mass and the center of rigidity, respectively, of the one-mass reduced system. The $x$-directional displacement of the center of mass of the one-mass system and the angle of rotation of the floor are denoted by $\bar{x}_{1}$ and $\bar{\theta}_{1}$. Then the governing equations of the undamped eigenvibration in the $x$-direction of the onemass system may be expressed by

$$
\begin{gathered}
\bar{m}_{1} \ddot{\bar{x}}_{1}+\bar{k}_{1}\left(\bar{x}_{1}+\bar{e}_{1} \bar{\theta}_{1}\right)=0 \\
\bar{I}_{1} \ddot{\bar{\theta}}_{1}+\bar{K}_{1} \bar{\theta}_{1}+\bar{e}_{1} \bar{k}_{1}\left(\bar{x}_{1}+\bar{e}_{1} \bar{\theta}_{1}\right)=0
\end{gathered}
$$

Let $\left\{\bar{u}_{1}^{(1)} \bar{\varphi}_{1}^{(1)}\right\}^{T}$ and $\bar{\omega}^{(1)}$ denote the lowest eigenmode and the undamped fundamental natural circular frequency of the one-mass reduced system. The lowest-mode vibration components of the one-mass system may be expressed in terms of $\left\{\bar{u}_{1}^{(1)} \bar{\varphi}_{1}^{(1)}\right\}^{T}$ and $\bar{\omega}^{(1)}$ by 


$$
\left\{\begin{array}{c}
\bar{x}_{1} \\
\bar{\theta}_{1}
\end{array}\right\}=A\left\{\begin{array}{c}
\bar{u}_{1}^{(1)} \\
\bar{\varphi}_{1}^{(1)}
\end{array}\right\} e^{i \bar{\omega}^{(1)} t} \quad(A \text { : arbitrary constant, } i \text { : imaginary unit })
$$

The translational and rotational accelerations of the center of mass corresponding to the lowest-mode vibration components can then be described by

$$
\left\{\begin{array}{c}
\ddot{\bar{x}}_{1} \\
\ddot{\overline{\theta_{1}}}
\end{array}\right\}=-\bar{\omega}^{(1) 2} A\left\{\begin{array}{c}
\bar{u}_{1}^{(1)} \\
\bar{\varphi}_{1}^{(1)}
\end{array}\right\} e^{i \bar{\omega}^{(1)} t}=-\bar{\omega}^{(1) 2}\left\{\begin{array}{c}
\bar{x}_{1} \\
\bar{\theta}_{1}
\end{array}\right\}
$$

Substitution of Eqs.(4) and (5) into Eqs.(2) and (3) provides

$$
\begin{gathered}
-\bar{\omega}^{(1) 2} \bar{m}_{1} \bar{x}_{1}+\bar{k}_{1}\left(\bar{x}_{1}+\bar{e}_{1} \bar{\theta}_{1}\right)=0 \\
-\bar{\omega}^{(1) 2} \bar{I}_{1} \bar{\theta}_{1}+\bar{K}_{1} \bar{\theta}_{1}+\bar{e}_{1} \bar{k}_{1}\left(\bar{x}_{1}+\bar{e}_{1} \bar{\theta}_{1}\right)=0
\end{gathered}
$$

The inverse eigenmode-problem formulation [20-22] yields the following expression for the $x$-directional story stiffness and the rotational stiffness of the one-mass reduced system.

$$
\begin{gathered}
\bar{k}_{1}=\frac{\bar{m}_{1} \bar{x}_{1}}{\bar{x}_{1}+\bar{e}_{1} \bar{\theta}_{1}} \bar{\omega}^{(1) 2}=\frac{\bar{m}_{1}}{1+\bar{e}_{1} \frac{\bar{\theta}_{1}}{\bar{x}_{1}}} \bar{\omega}^{(1) 2}=\frac{\bar{m}_{1}}{1+\bar{e}_{1} \frac{\bar{\varphi}_{1}^{(1)}}{\bar{u}_{1}^{(1)}} \bar{\omega}^{(1) 2}} \\
\bar{K}_{1}=\frac{\bar{I}_{1} \bar{\theta}_{1}-\bar{e}_{1} \bar{m}_{1} \bar{x}_{1}}{\bar{\theta}_{1}} \bar{\omega}^{(1) 2}=\frac{\bar{I}_{1} \frac{\bar{\theta}_{1}}{\bar{x}_{1}}-\bar{e}_{1} \bar{m}_{1}}{\frac{\bar{\theta}_{1}}{\bar{x}_{1}}} \bar{\omega}^{(1) 2}=\frac{\bar{I}_{1} \frac{\bar{\varphi}_{1}^{(1)}}{\bar{u}_{1}^{(1)}}-\bar{e}_{1} \bar{m}_{1}}{\frac{\bar{\varphi}_{1}^{(1)}}{\bar{u}_{1}^{(1)}}} \bar{\omega}^{(1) 2}
\end{gathered}
$$

Let us introduce the following conditions on the limited equivalence of the original model and the one-mass reduced system, i.e. the equivalence of the undamped fundamental natural circular frequency and the lowest-mode component ratio.

$$
\bar{\omega}^{(1)}=\omega^{(1)}
$$




$$
\frac{\bar{\varphi}_{1}^{(1)}}{\bar{u}_{1}^{(1)}}=\frac{\varphi_{10}^{(1)}}{u_{10}^{(1)}}
$$

Substitution of Eqs.(10) and (11) into Eqs.(8) and (9) leads to the solution of $\bar{k}_{1}$ and $\bar{K}_{1}$ to the inverse eigenmode problem.

$$
\begin{gathered}
\bar{k}_{1}=\frac{\bar{m}_{1}}{1+\bar{e}_{1} \frac{\varphi_{10}^{(1)}}{u_{10}^{(1)}}} \omega^{(1) 2} \\
\bar{K}_{1}=\frac{\bar{I}_{1} \frac{\varphi_{10}^{(1)}}{u_{10}^{(1)}}-\bar{e}_{1} \bar{m}_{1}}{\frac{\varphi_{10}^{(1)}}{u_{10}^{(1)}}} \omega^{(1) 2}
\end{gathered}
$$

\subsubsection{Transformation into two-mass system}

Consider a two-mass system, as shown in Fig.2, with the masses $\bar{m}_{1}, \bar{m}_{2}$ and the mass moments of inertia $\bar{I}_{1}, \bar{I}_{2}$ reduced from the original shear building model. There are several possibilities. In this paper two floor levels (5-th and 10-th) are selected as the representative ones. Each set of the masses and the mass moments of inertia between the representative floor levels are summed up into the representative floor level just above them. Both centers of mass of the two-mass system exist at the center of the floor and the centers of rigidity are located at the same point as the original model, i.e. $\bar{e}_{1}=\bar{e}_{2}=e$.

Let $\bar{k}_{1}, \bar{k}_{2}$ and $\bar{K}_{1}, \bar{K}_{2}$ denote the $x$-directional story stiffnesses and the rotational stiffnesses around the center of rigidity of the two-mass reduced system, respectively. The $x$ directional displacements of the centers of mass of the two-mass system and the angles of rotation of the floors are denoted by $\bar{x}_{1}, \bar{x}_{2}$ and $\bar{\theta}_{1}, \bar{\theta}_{2}$, respectively.

The governing equations of undamped free vibration of the two-mass reduced model may be expressed as

$$
\bar{m}_{1} \ddot{\bar{x}}_{1}+\bar{k}_{1}\left(\bar{x}_{1}+\bar{e}_{1} \bar{\theta}_{1}\right)-\bar{k}_{2}\left\{\left(\bar{x}_{2}-\bar{x}_{1}\right)+\bar{e}_{2}\left(\bar{\theta}_{2}-\bar{\theta}_{1}\right)\right\}=0
$$




$$
\begin{gathered}
\bar{m}_{2} \ddot{\bar{x}}_{2}+\bar{k}_{2}\left\{\left(\bar{x}_{2}-\bar{x}_{1}\right)+\bar{e}_{2}\left(\bar{\theta}_{2}-\bar{\theta}_{1}\right)\right\}=0 \\
\bar{I}_{1} \ddot{\bar{\theta}_{1}}+\bar{K}_{1} \bar{\theta}_{1}-\bar{K}_{2}\left(\bar{\theta}_{2}-\bar{\theta}_{1}\right)+\bar{e}_{1} \bar{k}_{1}\left(\bar{x}_{1}+\bar{e}_{1} \bar{\theta}_{1}\right)-\bar{e}_{2} \bar{k}_{2}\left\{\left(\bar{x}_{2}-\bar{x}_{1}\right)+\bar{e}_{2}\left(\bar{\theta}_{2}-\bar{\theta}_{1}\right)\right\}=0 \\
\bar{I}_{2} \ddot{\bar{\theta}_{2}}+\bar{K}_{2}\left(\bar{\theta}_{2}-\bar{\theta}_{1}\right)+\bar{e}_{2} \bar{k}_{2}\left\{\left(\bar{x}_{2}-\bar{x}_{1}\right)+\bar{e}_{2}\left(\bar{\theta}_{2}-\bar{\theta}_{1}\right)\right\}=0
\end{gathered}
$$

Let $\left\{\bar{u}_{1}^{(1)} \bar{u}_{2}^{(1)} \bar{\varphi}_{1}^{(1)} \bar{\varphi}_{2}^{(1)}\right\}^{T}$ and $\bar{\omega}^{(1)}$ denote the lowest eigenmode and the undamped fundamental natural circular frequency of the two-mass reduced system. The lowest-mode vibration components of the two-mass reduced system may be expressed by

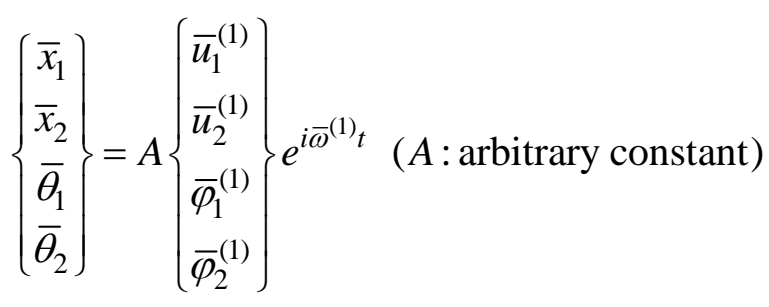

The translational and rotational accelerations of masses corresponding to the lowest-mode vibration components can then be described by

$$
\left\{\begin{array}{c}
\ddot{\bar{x}}_{1} \\
\ddot{\bar{x}}_{2} \\
\ddot{\bar{\theta}_{1}} \\
\ddot{\bar{\theta}_{2}}
\end{array}\right\}=-\bar{\omega}^{(1) 2} A\left\{\begin{array}{c}
\bar{u}_{1}^{(1)} \\
\bar{u}_{2}^{(1)} \\
\bar{\varphi}_{1}^{(1)} \\
\bar{\varphi}_{2}^{(1)}
\end{array}\right\} e^{i \bar{\omega}^{(1)} t}=-\bar{\omega}^{(1) 2}\left\{\begin{array}{c}
\bar{x}_{1} \\
\bar{x}_{2} \\
\bar{\theta}_{1} \\
\bar{\theta}_{2}
\end{array}\right\}
$$

Substitution of Eqs.(18) and (19) into Eqs.(14)-(17) provides

$$
\begin{gathered}
-\bar{m}_{1} \bar{\omega}^{(1) 2} \bar{x}_{1}+\bar{k}_{1}\left(\bar{x}_{1}+\bar{e}_{1} \bar{\theta}_{1}\right)-\bar{k}_{2}\left\{\left(\bar{x}_{2}-\bar{x}_{1}\right)+\bar{e}_{2}\left(\bar{\theta}_{2}-\bar{\theta}_{1}\right)\right\}=0 \\
-\bar{m}_{2} \bar{\omega}^{(1) 2} \bar{x}_{2}+\bar{k}_{2}\left\{\left(\bar{x}_{2}-\bar{x}_{1}\right)+\bar{e}_{2}\left(\bar{\theta}_{2}-\bar{\theta}_{1}\right)\right\}=0 \\
-\bar{I}_{1} \bar{\omega}^{(1) 2} \bar{\theta}_{1}+\bar{K}_{1} \bar{\theta}_{1}-\bar{K}_{2}\left(\bar{\theta}_{2}-\bar{\theta}_{1}\right)+\bar{e}_{1} \bar{k}_{1}\left(\bar{x}_{1}+\bar{e}_{1} \bar{\theta}_{1}\right)-\bar{e}_{2} \bar{k}_{2}\left\{\left(\bar{x}_{2}-\bar{x}_{1}\right)+\bar{e}_{2}\left(\bar{\theta}_{2}-\bar{\theta}_{1}\right)\right\}=0
\end{gathered}
$$




$$
-\bar{I}_{2} \bar{\omega}^{(1) 2} \bar{\theta}_{2}+\bar{K}_{2}\left(\bar{\theta}_{2}-\bar{\theta}_{1}\right)+\bar{e}_{2} \bar{k}_{2}\left\{\left(\bar{x}_{2}-\bar{x}_{1}\right)+\bar{e}_{2}\left(\bar{\theta}_{2}-\bar{\theta}_{1}\right)\right\}=0
$$

The inverse eigenmode-problem formulation [20-22] as described for the one-mass reduced model yields the following expression for the $x$-directional story stiffnesses and the rotational stiffnesses around the center of rigidity of the two-mass reduced system.

$$
\begin{gathered}
\bar{k}_{1}=\frac{\bar{m}_{1} \bar{x}_{1}+\bar{m}_{2} \bar{x}_{2}}{\bar{x}_{1}+\bar{e}_{1} \bar{\theta}_{1}} \bar{\omega}^{(1) 2} \\
\bar{k}_{2}=\frac{\bar{m}_{2} \bar{x}_{2}}{\bar{x}_{2}-\bar{x}_{1}+\bar{e}_{2}\left(\bar{\theta}_{2}-\bar{\theta}_{1}\right)} \bar{\omega}^{(1) 2} \\
\bar{K}_{1}=\frac{\bar{I}_{1} \bar{\theta}_{1}+\bar{I}_{2} \bar{\theta}_{2}-\bar{e}_{1}\left(\bar{m}_{1} \bar{x}_{1}+\bar{m}_{2} \bar{x}_{2}\right)}{\bar{\theta}_{1}} \bar{\omega}^{(1) 2} \\
\bar{K}_{2}=\frac{\bar{I}_{2} \bar{\theta}_{2}-\bar{e}_{2} \bar{m}_{2} \bar{x}_{2}}{\bar{\theta}_{2}-\bar{\theta}_{1}} \bar{\omega}^{(1) 2}
\end{gathered}
$$

As in the case of the one-mass reduced system, let us introduce the following conditions on the limited equivalence of the original model and the two-mass reduced system, i.e. the equivalence of the undamped fundamental natural circular frequency and the lowest-mode component ratios.

$$
\begin{gathered}
\bar{\omega}^{(1)}=\omega^{(1)} \\
\left.\left\{\begin{array}{l}
\bar{u}_{1}^{(1)} \\
\bar{u}_{2}^{(1)} \\
\bar{\varphi}_{1}^{(1)} \\
\bar{\varphi}_{2}^{(1)}
\end{array}\right\}=B\left\{\begin{array}{l}
u_{5}^{(1)} \\
u_{10}^{(1)} \\
\varphi_{5}^{(1)} \\
\varphi_{10}^{(1)}
\end{array}\right\} \Rightarrow \frac{\bar{\varphi}_{2}^{(1)}}{\bar{u}_{2}^{(1)}}=\frac{\varphi_{10}^{(1)}}{u_{10}^{(1)}}, \frac{\bar{\varphi}_{1}^{(1)}}{\bar{u}_{2}^{(1)}}=\frac{\varphi_{5}^{(1)}}{u_{10}^{(1)}}, \frac{\bar{u}_{1}^{(1)}}{\bar{u}_{2}^{(1)}}=\frac{u_{5}^{(1)}}{u_{10}^{(1)}}\right)
\end{gathered}
$$

where $B$ is an arbitrary constant. Substitution of Eqs.(28) and (29) into Eqs.(24)-(27) leads to the solution to the inverse eigenmode problem. 


$$
\begin{aligned}
& \bar{k}_{1}=\frac{\bar{m}_{1} \frac{u_{5}^{(1)}}{u_{10}^{(1)}}+\bar{m}_{2}}{\frac{u_{5}^{(1)}}{u_{10}^{(1)}}+\bar{e}_{1} \frac{\varphi_{5}^{(1)}}{u_{10}^{(1)}}} \omega^{(1) 2} \\
& \bar{k}_{2}=\frac{\bar{m}_{2}}{1-\frac{u_{5}^{(1)}}{u_{10}^{(1)}}+\bar{e}_{2}\left(\frac{\varphi_{10}^{(1)}}{u_{10}^{(1)}}-\frac{\varphi_{5}^{(1)}}{u_{10}^{(1)}}\right)} \omega^{(1) 2} \\
& \bar{K}_{1}=\frac{\bar{I}_{1} \frac{\varphi_{5}^{(1)}}{u_{10}^{(1)}}+\bar{I}_{2} \frac{\varphi_{10}^{(1)}}{u_{10}^{(1)}}-\bar{e}_{1}\left(\bar{m}_{1} \frac{u_{5}^{(1)}}{u_{10}^{(1)}}+\bar{m}_{2}\right)}{\frac{\varphi_{5}^{(1)}}{u_{10}^{(1)}}} \omega^{(1) 2} \\
& \bar{K}_{2}=\frac{\bar{I}_{2} \frac{\varphi_{10}^{(1)}}{u_{10}^{(1)}}-\bar{e}_{2} \bar{m}_{2}}{\frac{\varphi_{10}^{(1)}}{u_{10}^{(1)}}-\frac{\varphi_{5}^{(1)}}{u_{10}^{(1)}}} \omega^{(1) 2}
\end{aligned}
$$

\subsection{Limitations}

The proposed procedure applies to elastic, mono-symmetric, shear type buildings, whose centers of mass and centers of rigidity are all on the same two vertical axes. Extensions to more general models, e.g. setback building models, may be possible by introducing the inverse problem formulation for such models in place of Eqs.(12), (13) and Eqs.(30)-(33). This extension will be shown elsewhere.

\section{Reduction of earthquake input}

It has been confirmed through extensive investigations that the structural reduction explained in the previous section is insufficient from the viewpoint of computational accuracy. To compensate for this, a concept of reduction of earthquake input is introduced in this paper. 
Consider an $N$-story shear building model. Let $\mathbf{x}(t)=\left\{x_{1} \cdots x_{N} \theta_{1} \cdots \theta_{N}\right\}^{T}$ denote the displacement vector of centers of mass. The equations of motion of the original model subjected to a base acceleration $\ddot{u}_{g}(t)$ can be expressed by

$$
\mathbf{M} \ddot{\mathbf{x}}(t)+\mathbf{C} \dot{\mathbf{x}}(t)+\mathbf{K x}(t)=-\mathbf{M r} \ddot{u}_{g}(t)
$$

where $\mathbf{r}=\{1 \cdots 10 \cdots 0\}^{T}$ is the influence coefficient vector. The right-hand side of Eq.(34) is called 'part of seismic inertia force'. Its physical meaning is shown in Fig.3.

Let $\overline{\mathbf{M}}, \overline{\mathbf{K}}, \overline{\mathbf{C}}$ and $\overline{\mathbf{x}}(t)$ denote the mass matrix, the stiffness matrix, the damping matrix and the displacement vector of centers of mass of the reduced model. Consider the equations of motion of the reduced model subjected to a reduced input force $\overline{\mathbf{f}}(t)$ at the centers of mass. Then the equations of motion of the reduced model may be described by

$$
\overline{\mathbf{M}} \ddot{\overline{\mathbf{x}}}(t)+\overline{\mathbf{C}} \dot{\overline{\mathbf{x}}}(t)+\overline{\mathbf{K}} \overline{\mathbf{x}}(t)=\overline{\mathbf{f}}(t)
$$

It is assumed here that the reduced earthquake input $\overline{\mathbf{f}}(t)$ can be derived from the limited equivalence of the displacements of centers of mass at the representative floors in the case where the original model and the reduced model resist with the restoring force only. These assumptions and conditions are described by

$$
\begin{aligned}
& \mathbf{K} \mathbf{x}^{*}=-\mathbf{M r} \ddot{u}_{g}(t) \\
& \overline{\mathbf{K}} \overline{\mathbf{x}}^{*}=\overline{\mathbf{f}}(t) \\
& \overline{\mathbf{x}}^{*}=\mathbf{T} \mathbf{x}^{*}
\end{aligned}
$$

where $\mathbf{T}$ denotes the transformation matrix positioning the representative floor number in the original model. Equations (36) and (37) mean that both models resist statically only in this situation. On the other hand, Eq.(38) requires the equivalence of the displacements of centers of mass at the representative floors of both models. Even if the natural periods, mode shapes 
and damping ratios of the original model and the reduced model are equivalent, the dynamic responses of these models may be different. This is because the modal participation factors of these models may exhibit different values. To compensate for this difference, the inertia forces are modified by employing the equivalence of the static stiffness. It should be remarked again that the displacements $\mathbf{x}^{*}$ and $\overline{\mathbf{x}}^{*}$ have been introduced only for constructing the reduced earthquake input force $\overline{\mathbf{f}}(t)$ and do not express the actual displacements.

Substitution of Eq.(38) into Eq.(37) provides

$$
\overline{\mathbf{f}}(t)=\overline{\mathbf{K}} \mathbf{T} \mathbf{x}^{*}
$$

From Eq.(36), the following relation can be derived.

$$
\mathbf{x}^{*}=-\mathbf{K}^{-1} \mathbf{M r}_{g}(t)
$$

Substitution of Eq.(40) into Eq.(39) leads to the following expression of the reduced earthquake input force.

$$
\overline{\mathbf{f}}(t)=-\overline{\mathbf{K}} \mathbf{T} \mathbf{K}^{-1} \mathbf{M r} \ddot{u}_{g}(t)
$$

It should be remarked that, if the earthquake response is limited to an elastic range, it is sufficient to compute $\mathbf{K}^{-1}$ once. This is not computationally demanding. Fig.4 shows the schematic diagram of the reduction process of earthquake input and the reduced earthquake input forces on the reduced model. Ont the other hand, Fig.5 illustrates the simple sum of earthquake input forces.

Since simple examples are useful for understanding of the proposed concept, a one-mass system and a two-mass system are dealt with in the following.

\subsection{One-mass system}

For this model, part of Eq.(38) can be expressed by 


$$
\begin{gathered}
\bar{x}_{1}^{*}=x_{10}{ }^{*} \\
\bar{\theta}_{1}^{*}=\theta_{10}{ }^{*}
\end{gathered}
$$

The transformation matrix $\mathbf{T}$ in Eq.(38) for this model is described by

$$
\mathbf{T}=\left[\begin{array}{llllllllllllllllllll}
0 & 0 & 0 & 0 & 0 & 0 & 0 & 0 & 0 & 1 & 0 & 0 & 0 & 0 & 0 & 0 & 0 & 0 & 0 & 0 \\
0 & 0 & 0 & 0 & 0 & 0 & 0 & 0 & 0 & 0 & 0 & 0 & 0 & 0 & 0 & 0 & 0 & 0 & 0 & 1
\end{array}\right]
$$

\subsection{Two-mass system}

For this model, part of Eq.(38) can be expressed by

$$
\begin{aligned}
& \bar{x}_{1}{ }^{*}=x_{5}{ }^{*}, \bar{x}_{2}{ }^{*}=x_{10}{ }^{*} \\
& \bar{\theta}_{1}^{*}=\theta_{5}{ }^{*}, \bar{\theta}_{2}{ }^{*}=\theta_{10}{ }^{*}
\end{aligned}
$$

The transformation matrix $\mathbf{T}$ in Eq.(38) for this model is described by

$$
\mathbf{T}=\left[\begin{array}{llllllllllllllllllll}
0 & 0 & 0 & 0 & 1 & 0 & 0 & 0 & 0 & 0 & 0 & 0 & 0 & 0 & 0 & 0 & 0 & 0 & 0 & 0 \\
0 & 0 & 0 & 0 & 0 & 0 & 0 & 0 & 0 & 1 & 0 & 0 & 0 & 0 & 0 & 0 & 0 & 0 & 0 & 0 \\
0 & 0 & 0 & 0 & 0 & 0 & 0 & 0 & 0 & 0 & 0 & 0 & 0 & 0 & 1 & 0 & 0 & 0 & 0 & 0 \\
0 & 0 & 0 & 0 & 0 & 0 & 0 & 0 & 0 & 0 & 0 & 0 & 0 & 0 & 0 & 0 & 0 & 0 & 0 & 1
\end{array}\right]
$$

\section{Numerical examples}

Consider a three-dimensional mono-symmetric ten-story shear building model, as shown in Fig.1(a), with only $x$-directional constant eccentricity subjected to three representative ground motions (El Centro NS 1940, Taft EW 1952 and Hachinohe NS 1968). Table 1 shows the structural parameters of the original ten-story model. The floor size is given by $L_{X}=L_{Y}=40(\mathrm{~m})$. Then floor masses are given by $m_{i}=1000 L_{X} L_{Y}=1.6 \times 10^{6}(\mathrm{~kg})$.

Based on the inverse eigenmode-problem formulation [20-22], the $x$-directional story stiffnesses are determined by 


$$
k_{i}=\hat{\omega}^{(1) 2} \sum_{j=i}^{N} j m_{j}
$$

where $\hat{\omega}^{(1)}$ denotes the undamped fundamental natural circular frequency of the model in the case of no eccentricity. Equation (46) is derived from the assumption of the straight-line lowest eigenmode in the case of no eccentricity. The fundamental natural period of the original model in the case of no eccentricity is assumed to be $\hat{T}=1.0(\mathrm{~s})$.

The eccentricity ratio is given by $R_{X i}=e_{i} / r_{X i}=0.2$ where $r_{X i}=\sqrt{K_{i} / k_{i}}$ and the $y$ directional stiffness ratio to the $x$-direction is given by $\alpha=0.5$. The damping matrix of the original model is assumed to be stiffness-proportional and is expressed by $\mathbf{C}=\left(2 h^{(1)} / \omega^{(1)}\right) \mathbf{K}$. On the other hand, the damping matrix of the reduced model is given by $\overline{\mathbf{C}}=\left(2 \bar{h}^{(1)} / \bar{\omega}^{(1)}\right) \overline{\mathbf{K}}$. The damping ratio is assumed to be $h^{(1)}=\bar{h}^{(1)}=0.02$. The Newmark- $\beta$ method $(\beta=1 / 4)$ has been used and the time increment of numerical integration has been set as 0.002(s).

\subsection{One-mass system}

Consider first the reduction into a one-mass system. Table 2 presents the structural parameters of the one-mass reduced model.

Fig.6 shows the comparison of top-floor $x$-directional displacements of center of mass among the ten-story original model, the one-mass reduced model under reduced earthquake input and the one-mass reduced model under simple earthquake input for El Centro NS 1940. It can be observed that the one-mass reduced model under reduced earthquake input can simulate the response of the original model within a reasonable accuracy and the transformation of earthquake input forces into a set of reduced input forces is inevitable for accurate simulation of the earthquake response of the original model by the reduced structural model.

Fig.7 illustrates the comparison of angles of floor rotation among the ten-story original model, the one-mass reduced model under reduced earthquake input and the one-mass reduced model under simple earthquake input for El Centro NS 1940. It can be seen that, 
although the one-mass reduced model under reduced earthquake input can simulate the response of the original model within a reasonable accuracy, the accuracy level deteriorates compared to the displacements of center of mass. This is because the angle of floor rotation in the second eigenmode is relatively large compared to that in the lowest eigenmode and the compensation by the reduced earthquake input is not sufficient in the evaluation of the angle of floor rotation.

Fig.8 presents the comparison of displacements of the positive corner column (see Fig.1(b)) among the ten-story original model, the one-mass reduced model under reduced earthquake input and the one-mass reduced model under simple earthquake input for $\mathrm{El}$ Centro NS 1940. It can be observed that the one-mass reduced model under reduced earthquake input can simulate the response of the original model within a reasonable accuracy and the accuracy level is between the displacement of center of mass and the angle of floor rotation.

Fig.9 indicates the comparison of displacements of the negative corner column (see Fig.1(b)) among the ten-story original model, the one-mass reduced model under reduced earthquake input and the one-mass reduced model under simple earthquake input for $\mathrm{El}$ Centro NS 1940. As in Fig.8, it can be observed that the one-mass reduced model under reduced earthquake input can simulate the response of the original model within a reasonable accuracy and the accuracy level is between the displacement of center of mass and the angle of floor rotation.

\subsection{Two-mass system}

Table 3 illustrates the structural parameters of the two-mass reduced model. The natural periods of the original model, the two-mass reduced model and the one-mass reduced model are shown in Table 4. It can be seen that, since the present paper deals with only the model with a common center of mass and a common center of rigidity throughout the stories, the natural periods of the reduced models coincide with those of the original model. Fig.10 shows the effective modal masses divided by the total mass of the original model. The 
effective modal masses larger than the fourth mode are omitted for the original model. Fig.11 illustrates the eigenmodes multiplied by the modal participation factors for the original model, the two-mass reduced model and the one-mass reduced model. A small difference can be seen and this problem is compensated by the introduction of the procedure of reduction of earthquake input.

Fig.12 presents the comparison of the reduced earthquake input and simple earthquake input for the two-mass reduced model under El Centro NS 1940. It can be observed that the reduced earthquake input is slightly magnified from the simple earthquake input.

Fig.13 shows the comparison of displacements of center of mass among the ten-story original model, the two-mass reduced model under reduced earthquake input and the onemass reduced model under reduced earthquake input for El Centro NS 1940. It can be seen that the accuracy level of the two-mass system is higher than that of the one-mass system.

Fig.14 illustrates the comparison of angles of floor rotation among the ten-story original model, the two-mass reduced model under reduced earthquake input and the one-mass reduced model under reduced earthquake input for El Centro NS 1940. Fig.15 presents the comparison of displacements of the positive corner column (see Fig.1(b)) among the ten-story original model, the two-mass reduced model under reduced earthquake input and the onemass reduced model under reduced earthquake input for El Centro NS 1940. On the other hand, Fig.16 indicates the comparison of displacements of the negative corner column (see Fig.1(b)) among the ten-story original model, the two-mass reduced model under reduced earthquake input and the one-mass reduced model under reduced earthquake input for $\mathrm{El}$ Centro NS 1940. From Figs.14-16, it can be understood that the accuracy level of the twomass system is higher than that of the one-mass system as in Fig.13.

\subsection{Results for three representative earthquake ground motions}

Table 5 shows the comparison of various responses among the ten-story original model, the two-mass reduced model under reduced earthquake input and the one-mass reduced model under reduced earthquake input for three representative ground motions (El Centro NS 1940, 
Taft EW 1952 and Hachinohe NS 1968). In Table 5, not only the actual responses but also the errors from the responses of the original model are presented. It can be observed that the two-mass reduced model can simulate the response of the original model more accurately than the one-mass reduced model for all of three representative ground motions except a few cases.

\subsection{Comparison in terms of modal responses}

Figs.17(a)-(d) show the comparison of modal responses between the ten-story original model and the two-mass reduced model under reduced earthquake input for El Centro NS 1940. The top-floor $x$-directional displacements of center of mass in the lowest two modal responses are compared in Fig.17(a). It can be observed that the second mode contributes significantly to the total response because the natural period of the second mode is close to that of the fundamental mode. It appears from Fig.17(a) that the lowest modal response of the ten-story original model and that of the two-mass reduced model under reduced earthquake input coincide well. This is supported by the fact that the fundamental natural frequencies, the lowest-mode damping ratios and the lowest-eigenmode components at the top floor of both models coincide perfectly due to Eqs.(28), (29) and the assumption $h^{(1)}=\bar{h}^{(1)}=0.02$. However, it should be remarked that the eigenmodes multiplied by the modal participation factors in the lowest-mode vibration of both models are different (see Fig.11) and the lowest modal response of the ten-story original model and that of the two-mass reduced model under reduced earthquake input are also different due to the difference of the eigenmodes multiplied by the modal participation factors (see Fig.11). This difference is reduced by introducing the concept of reduced earthquake input. As for the modal response in the second-mode vibration, the second natural frequencies, the second-mode damping ratios and the second eigenmode components at the top floor of both models also coincide perfectly in this model. However, the eigenmodes multiplied by the modal participation factors in the second mode of both models are different (see Fig.11) and the second modal response of the ten-story original model and that of the two-mass reduced model under reduced earthquake input are also different. 
The angles of top-floor rotation in the lowest two modal responses are compared in Fig.17(b). It can be seen that the second-mode response appears in the reverse direction to the lowest-mode response. The $x$-directional displacements of top-story positive and negative corner columns in the lowest two modal responses are compared in Fig.17(c) and (d), respectively. It can be understood that the two-mass reduced model under reduced earthquake input can simulate the lowest two modal responses of the original model not only in the topfloor $x$-directional displacement of center of mass but also in the angle of top-floor rotation and in the $x$-directional displacements of top-story positive and negative corner columns.

It should be remarked finally that the present reduced model can simulate only the displacements at the representative floor levels. If the interstory drifts are needed, the selection of the representative floor levels should be made carefully. When the interstory drift at the top story is required, the top two floor levels should be selected as the representative floor levels. This issue has to be discussed in the future.

\section{Various eccentricities and lateral-torsional stiffness ratios}

In order to investigate the accuracy of the proposed reduction method for various eccentricities and lateral-torsional stiffness ratios, additional analysis has been conducted for El Centro NS 1940.

Table 6 shows the comparison of accuracies among the original model, the two-mass reduced model under reduced earthquake input and the two-mass reduced model under simple earthquake input (El Centro NS 1940) for various eccentricities $e_{i}=1.70,3.40,5.10(m)$ $\left(R_{X i}=0.1,0.2,0.3\right)$. The parameter $r_{X i}=\sqrt{K_{i} / k_{i}}$ has been set as $r_{X i}=17.0(m)$. There is no special difference from the accuracy for the model in Sections 4.1 and 4.2.

Table 7 presents the comparison of accuracies among the original model, the two-mass reduced model under reduced earthquake input and the two-mass reduced model under simple earthquake input (El Centro NS 1940) for various lateral-torsional stiffness ratios $r_{X i}=34.0,17.0,11.3(m)\left(R_{X i}=0.1,0.2,0.3\right)$. The eccentricity has been set as $e_{i}=3.40(m)$. There is no special difference from the accuracy for the model in Sections 4.1 and 4.2. 


\section{Application to model with non-proportional damping}

In order to show that the proposed method can be applied to non-classically damped models, an example ten-story model is considered which includes passive viscous dampers with a constant damping coefficient only at the lower five stories. All the dampers are located at the center of mass and the damping coefficient is determined so that the approximate additional lowest-mode damping ratio attains 0.10 .

Table 8 shows the comparison of various responses among the ten-story original model, the one-mass reduced model under reduced earthquake input and the one-mass reduced model under simple earthquake input for El Centro NS 1940. It can be seen that, although the accuracy is reduced slightly, a reasonable response evaluation can be made

\section{Conclusions}

An enhanced reduced model is proposed for elastic earthquake response analysis of a class of mono-symmetric shear building structures with constant eccentricity. The principal results may be summarized as follows.

(1) The proposed reduction method consists of two parts. The first stage is the construction of a reduced structural model with the degrees of freedom at representative floor levels only. In this stage, an inverse eigenmode-problem formulation is used to guarantee the equivalence of the undamped fundamental natural frequency and the lowest-mode component ratios at the representative floor levels between the original model and the reduced model. More specifically, the reduced model is constructed so as to have the same fundamental natural frequency and the same lowest-mode component ratios at the representative floor levels as those of the original model.

(2) The second stage is the transformation of earthquake input forces into a set of reduced input forces. This transformation utilizes the static equivalence of lateral-torsional stiffness between these two models and is introduced to enhance the accuracy level of the reduced model. 
(3) Reduction examples of a three-dimensional mono-symmetric ten-story shear building model with constant eccentricity into a one-mass system and a two-mass system revealed that the proposed reduction method possesses a reasonable and acceptable accuracy and the two-mass system exhibits a higher accuracy than the one-mass system.

(4) It has been demonstrated numerically that the transformation of earthquake input forces into a set of reduced input forces is inevitable for accurate simulation of the earthquake response of the original model by the proposed reduced structural model.

(5) It has been shown that the proposed reduction method can be applied to non-classically damped models for which the classical normal mode decomposition is not possible.

Only the buildings with constant eccentricity throughout the stories have been treated in this paper for a simple presentation of a new model reduction method. It has been confirmed that this model reduction theory is applicable to more general buildings with irregular eccentricities, e.g. setback buildings. That theory will be presented in the future.

\section{Acknowledgements}

This research is partly supported by the Grant-in-Aid for Scientific Research (No. 21360267) of the Japanese Society for the Promotion of Science. This support is gratefully acknowledged.

\section{References}

[1] Kan CL Chopra AK. Elastic earthquake analysis of torsionally coupled multistorey buildings. Earthquake Engineering and Structural Dynamics 1977; 5(4): 395-412.

[2] Tso WK, Dempsey KM. Seismic torsional provisions for dynamic eccentricity. Earthquake Engineering and Structural Dynamics 1980; 8(3): 75-289.

[3] Chandler A. M. and Hutchinson G. L. Torsional coupling effects in the earthquake response of asymmetric buildings. Engineering Structures 1986; 8: 222-236.

[4] Hejal R, Chopra, AK. Earthquake analysis of a class of torsionally-coupled buildings. 
Earthquake Engineering and Structural Dynamics 1989; 18(3): 305-323.

[5] Maheri MR, Chandler AM., Bassett RH. Coupled lateral-torsional behaviour of frame structures under earthquake loading. Earthquake Engineering and Structural Dynamics 1991; 20(1): 61-85.

[6] Nakamura T, Nakamura,Y. Stiffness design of 3-D shear buildings for specified seismic drifts. Journal of Structural. Engineering ASCE 1993; 119(1): 50-68.

[7] De la Llera JC, Chopra AK. Accidental torsion in buildings due to stiffness uncertainty. Earthquake Engineering and Structural Dynamics 1994; 23(2): 117-136.

[8] Duan XN, Chandler AM. Seismic torsional response and design procedures for a class of setback frame buildings. Earthquake Engineering and Structural Dynamics 1995; 24(5): 761-777.

[9] Anastassiadis K, Athanatopoulos A, Makarios T. Equivalent static eccentricities in the simplified methods of seismic analysis of buildings. Earthquake Spectra 1998; 14(1): 1-34.

[10] Chopra AK, Goel RK. A modal pushover analysis procedure to estimate seismic demands for unsymmetric-plan buildings. Earthquake Engineering and Structural Dynamics 2004; 33(8): 903-927.

[11] Rafezy B., Zare A., Howson WP. Coupled lateral-torsional frequencies of asymmetric, three-dimensional frame structures. International Journal of Solids and Structures 2007; 44(1): 128-144.

[12] De Stefano M, Pintucchi B. A review of research on seismic behavior of irregular building structures since 2002. Bulletin of Earthquake Engineering 2008; 6(2): 285-308.

[13] Stathopoulos KG, Anagnostopoulos SA. Inelastic torsion of multistory buildings under earthquake excitations. Earthquake Engineering and Structural Dynamics 2005; 34: 1449-1465.

[14] Athanatopoulou AM, Makarios T, Anastassiadis K. 2006. Earthquake analysis of isotropic asymmetric multistorey buildings. Journal of the Structural Design of Tall \& Special Buildings 2006; 15(4): 417-443.

[15] Lucchini A, Monti G, Kunnath S. Seismic behavior of single-story asymmetric-plan 
buildings under uniaxial excitation. Earthquake Engineering and Structural Dynamics 2009; 38(9): 1053-1070.

[16] Stathopoulos KG, Anagnostopoulos SA. Accidental design eccentricity: Is it important for the inelastic response of buildings to strong earthquakes? Soil Dynamics and Earthqiake Engineering 2010; 30: 782-797.

[17] English Edition of Preliminary Reconnaissance Report of the 1995 Hyogoken-Nanbu Earthquake, Architectural Institute of Japan, March 1995.

[18] Takewaki I. Critical Excitation Methods in Earthquake Engineering. Elsevier 2006.

[19] Takewaki I, Yoshitomi S, Uetani K, Tsuji M. Non-monotonic optimal damper placement via steepest direction search. Earthquake Engineering and Structural Dynamics 1999; 28(6): 655-670.

[20] Nakamura T, Yamane T. Optimum design and earthquake-response constrained design of elastic shear buildings. Earthquake Engineering and Structural Dynamics 1986; 14(5): 797-815.

[21] Takewaki I, Nakamura T. Hybrid inverse mode problems for FEM-shear models, Journal of Engineering Mechanics ASCE 1995; 121(8): 873-880.

[22] Takewaki I, Nakamura T, Hirayama K. Seismic frame design via inverse mode design of frame-ground systems. Soil Dynamics and Earthquake Engineering 1998; 17(3):153-163. 
Table 1 Structural parameters of original model

\begin{tabular}{|c|c|c|c|c|c|c|}
\hline $\begin{array}{c}\text { story } \\
\text { number }\end{array}$ & $m_{i}(\mathrm{~kg})$ & $I_{i}\left(\mathrm{~kg} \cdot \mathrm{m}^{2}\right)$ & $k_{i}(\mathrm{~N} / \mathrm{m})$ & $e_{i}(\mathrm{~m})$ & $K_{i}(\mathrm{~N} \cdot \mathrm{m} / \mathrm{rad})$ & $r_{X i}(\mathrm{~m})$ \\
\hline 1 & $1.60 \times 10^{6}$ & $4.27 \times 10^{8}$ & $3.47 \times 10^{9}$ & 3.40 & $1.00 \times 10^{12}$ & 17.0 \\
\hline 2 & $1.60 \times 10^{6}$ & $4.27 \times 10^{8}$ & $3.41 \times 10^{9}$ & 3.40 & $9.84 \times 10^{11}$ & 17.0 \\
\hline 3 & $1.60 \times 10^{6}$ & $4.27 \times 10^{8}$ & $3.28 \times 10^{9}$ & 3.40 & $9.47 \times 10^{11}$ & 17.0 \\
\hline 4 & $1.60 \times 10^{6}$ & $4.27 \times 10^{8}$ & $3.10 \times 10^{9}$ & 3.40 & $8.93 \times 10^{11}$ & 17.0 \\
\hline 5 & $1.60 \times 10^{6}$ & $4.27 \times 10^{8}$ & $2.84 \times 10^{9}$ & 3.40 & $8.20 \times 10^{11}$ & 17.0 \\
\hline 6 & $1.60 \times 10^{6}$ & $4.27 \times 10^{8}$ & $2.53 \times 10^{9}$ & 3.40 & $7.29 \times 10^{11}$ & 17.0 \\
\hline 7 & $1.60 \times 10^{6}$ & $4.27 \times 10^{8}$ & $2.15 \times 10^{9}$ & 3.40 & $6.20 \times 10^{11}$ & 17.0 \\
\hline 8 & $1.60 \times 10^{6}$ & $4.27 \times 10^{8}$ & $1.71 \times 10^{9}$ & 3.40 & $4.92 \times 10^{11}$ & 17.0 \\
\hline 9 & $1.60 \times 10^{6}$ & $4.27 \times 10^{8}$ & $1.20 \times 10^{9}$ & 3.40 & $3.46 \times 10^{11}$ & 17.0 \\
\hline 10 & $1.60 \times 10^{6}$ & $4.27 \times 10^{8}$ & $6.32 \times 10^{8}$ & 3.40 & $1.82 \times 10^{11}$ & 17.0 \\
\hline
\end{tabular}

Table 2 Structural parameters of one-mass reduced model

\begin{tabular}{|c|c|c|c|c|c|c|}
\hline $\begin{array}{c}\text { story } \\
\text { number }\end{array}$ & $\bar{m}_{j}(\mathrm{~kg})$ & $\bar{I}_{j}\left(\mathrm{~kg} \cdot \mathrm{m}^{2}\right)$ & $\bar{k}_{j}(\mathrm{~N} / \mathrm{m})$ & $\bar{e}_{j}(\mathrm{~m})$ & $\bar{K}_{j}(\mathrm{~N} \cdot \mathrm{m} / \mathrm{rad})$ & $\bar{r}_{X j}(\mathrm{~m})$ \\
\hline 1 & $1.60 \times 10^{7}$ & $4.27 \times 10^{9}$ & $6.32 \times 10^{8}$ & 3.40 & $1.82 \times 10^{11}$ & 17.0 \\
\hline
\end{tabular}

Table 3 Structural parameters of two-mass reduced model

\begin{tabular}{|c|c|c|c|c|c|c|}
\hline $\begin{array}{c}\text { story } \\
\text { number }\end{array}$ & $\bar{m}_{j}(\mathrm{~kg})$ & $\bar{I}_{j}\left(\mathrm{~kg} \cdot \mathrm{m}^{2}\right)$ & $\bar{k}_{j}(\mathrm{~N} / \mathrm{m})$ & $\bar{e}_{j}(\mathrm{~m})$ & $\bar{K}_{j}(\mathrm{~N} \cdot \mathrm{m} / \mathrm{rad})$ & $\bar{r}_{X j}(\mathrm{~m})$ \\
\hline 1 & $8.00 \times 10^{6}$ & $2.13 \times 10^{9}$ & $9.47 \times 10^{8}$ & 3.40 & $2.73 \times 10^{11}$ & 17.0 \\
\hline 2 & $8.00 \times 10^{6}$ & $2.13 \times 10^{9}$ & $6.32 \times 10^{8}$ & 3.40 & $1.82 \times 10^{11}$ & 17.0 \\
\hline
\end{tabular}


Table 4 Natural periods of original model, two-mass reduced model and one-mass reduced model

\begin{tabular}{|c|c|c|c|}
\hline \multirow{2}{*}{$\begin{array}{c}\text { Mode } \\
\text { number }\end{array}$} & \multicolumn{3}{|c|}{ Natural period } \\
\cline { 2 - 4 } & $\begin{array}{c}\text { Original } \\
\text { model }\end{array}$ & $\begin{array}{c}\text { Two-mass } \\
\text { reduced model }\end{array}$ & $\begin{array}{c}\text { One-mass } \\
\text { reduced model }\end{array}$ \\
\hline 1 & 1.087661 & 1.087661 & 1.087661 \\
\hline 2 & 0.883987 & 0.883987 & 0.883987 \\
\hline 3 & 0.444036 & 0.444036 & \\
\hline 4 & 0.360886 & 0.360886 & \\
\hline
\end{tabular}

Table 5 Comparison among original model, two-mass reduced model under reduced earthquake input and one-mass reduced model under reduced earthquake input

\begin{tabular}{|c|c|c|c|c|c|c|}
\hline $\begin{array}{l}\text { Ground } \\
\text { motion }\end{array}$ & Response quantity & $\begin{array}{c}\text { Original } \\
\text { model }\end{array}$ & $\begin{array}{c}\text { Two-mass } \\
\text { reduced } \\
\text { model }\end{array}$ & $\begin{array}{c}\text { Error } \\
(\%)\end{array}$ & $\begin{array}{c}\text { One-mass } \\
\text { reduced } \\
\text { model }\end{array}$ & $\begin{array}{c}\text { Error } \\
(\%)\end{array}$ \\
\hline \multirow{4}{*}{$\begin{array}{l}\text { El Centro } \\
\text { NS } 1940\end{array}$} & $\begin{array}{l}\text { Disp. of center of } \\
\text { mass (mm) }\end{array}$ & 161 & 157 & 2.29 & 153 & 4.73 \\
\hline & $\begin{array}{l}\text { Angle of rotation } \\
\left(\times 10^{-3} \mathrm{rad}\right)\end{array}$ & 10.5 & 10.0 & 4.87 & 9.85 & 6.28 \\
\hline & $\begin{array}{l}\text { Positive column } \\
\text { disp.(mm) }\end{array}$ & 207 & 199 & 3.69 & 192 & 6.94 \\
\hline & $\begin{array}{l}\text { Negative column } \\
\text { disp.(mm) }\end{array}$ & 307 & 289 & 5.88 & 274 & 10.9 \\
\hline \multirow{4}{*}{$\begin{array}{c}\text { Taft EW } \\
1952\end{array}$} & $\begin{array}{l}\text { Disp. of center of } \\
\text { mass (mm) }\end{array}$ & 75.6 & 69.6 & 7.95 & 71.4 & 5.60 \\
\hline & $\begin{array}{l}\text { Angle of rotation } \\
\left(\times 10^{-3} \mathrm{rad}\right)\end{array}$ & 3.04 & 2.89 & 5.18 & 2.89 & 4.95 \\
\hline & $\begin{array}{l}\text { Positive column } \\
\text { disp.(mm) }\end{array}$ & 100 & 93.9 & 6.24 & 89.9 & 10.3 \\
\hline & $\begin{array}{l}\text { Negative column } \\
\text { disp.(mm) }\end{array}$ & 84.8 & 82.9 & 2.22 & 80.8 & 4.76 \\
\hline \multirow{4}{*}{$\begin{array}{l}\text { Hachinohe } \\
\text { NS } 1968\end{array}$} & $\begin{array}{l}\text { Disp. of center of } \\
\text { mass (mm) }\end{array}$ & 117 & 114 & 2.85 & 110 & 5.58 \\
\hline & $\begin{array}{l}\text { Angle of rotation } \\
\left(\times 10^{-3} \mathrm{rad}\right)\end{array}$ & 5.94 & 5.71 & 3.83 & 5.56 & 6.37 \\
\hline & $\begin{array}{l}\text { Positive column } \\
\text { disp.(mm) }\end{array}$ & 113 & 111 & 1.36 & 110 & 2.37 \\
\hline & $\begin{array}{l}\text { Negative column } \\
\text { disp.(mm) }\end{array}$ & 194 & 189 & 3.04 & 183 & 5.97 \\
\hline
\end{tabular}


Table 6 Comparison of accuracies among original model, two-mass reduced model under reduced earthquake input and two-mass reduced model under simple earthquake input (El Centro NS 1940) for various eccentricities

\begin{tabular}{|c|c|c|c|c|c|c|c|}
\hline \multirow[b]{2}{*}{$\begin{array}{l}r_{X i} \\
(\mathrm{~m})\end{array}$} & \multirow[b]{2}{*}{$\begin{array}{l}e_{i}(\mathrm{~m}) \\
\left(R_{X i}\right)\end{array}$} & \multirow[b]{2}{*}{ Response quantity } & \multirow[b]{2}{*}{$\begin{array}{c}\text { Original } \\
\text { model }\end{array}$} & \multicolumn{4}{|c|}{ Two-mass reduced model } \\
\hline & & & & $\begin{array}{l}\text { Reduced } \\
\text { earthquake } \\
\text { input }\end{array}$ & $\begin{array}{l}\text { Error } \\
(\%)\end{array}$ & $\begin{array}{c}\text { Simple } \\
\text { earthquake } \\
\text { input }\end{array}$ & $\begin{array}{l}\text { Error } \\
(\%)\end{array}$ \\
\hline \multirow{12}{*}{17.0} & \multirow{4}{*}{$\begin{array}{l}1.70 \\
(0.1)\end{array}$} & $\begin{array}{l}\text { Disp. of center of } \\
\text { mass }(\mathrm{mm})\end{array}$ & 202 & 197 & -2.10 & 172 & -14.9 \\
\hline & & $\begin{array}{l}\text { Angle of rotation } \\
\qquad\left(\times 10^{-3} \mathrm{rad}\right)\end{array}$ & 8.37 & 7.97 & -4.81 & 6.91 & -17.4 \\
\hline & & $\begin{array}{l}\text { Positive column } \\
\text { disp. (mm) }\end{array}$ & 221 & 206 & -6.89 & 178 & -19.4 \\
\hline & & $\begin{array}{l}\text { Negative column } \\
\text { disp. (mm) }\end{array}$ & 289 & 278 & -3.89 & 241 & -16.6 \\
\hline & \multirow{4}{*}{$\begin{array}{l}3.40 \\
(0.2)\end{array}$} & $\begin{array}{c}\text { Disp. of center of } \\
\text { mass }(\mathrm{mm})\end{array}$ & 161 & 157 & -2.29 & 137 & -15.1 \\
\hline & & $\begin{array}{c}\text { Angle of rotation } \\
\left(\times 10^{-3} \mathrm{rad}\right)\end{array}$ & 10.5 & 10.0 & -4.87 & 8.67 & -17.5 \\
\hline & & $\begin{array}{l}\text { Positive column } \\
\text { disp. (mm) }\end{array}$ & 207 & 199 & -3.68 & 173 & -16.4 \\
\hline & & $\begin{array}{l}\text { Negative column } \\
\text { disp. (mm) }\end{array}$ & 307 & 289 & -5.88 & 250 & -18.5 \\
\hline & \multirow{4}{*}{$\begin{array}{l}5.10 \\
(0.3)\end{array}$} & $\begin{array}{l}\text { Disp. of center of } \\
\text { mass }(\mathrm{mm})\end{array}$ & 204 & 202 & -0.98 & 176 & -13.8 \\
\hline & & $\begin{array}{l}\text { Angle of rotation } \\
\left(\times 10^{-3} \mathrm{rad}\right)\end{array}$ & 9.68 & 9.31 & -3.81 & 8.09 & -16.5 \\
\hline & & $\begin{array}{c}\text { Positive column } \\
\text { disp. (mm) }\end{array}$ & 197 & 192 & -2.65 & 167 & -15.4 \\
\hline & & $\begin{array}{l}\text { Negative column } \\
\text { disp. (mm) }\end{array}$ & 271 & 258 & -4.69 & 224 & -17.3 \\
\hline
\end{tabular}


Table 7 Comparison of accuracies among original model, two-mass reduced model under reduced earthquake input and two-mass reduced model under simple earthquake input (El Centro NS 1940) for various lateral-torsional stiffness ratios

\begin{tabular}{|c|c|c|c|c|c|c|c|}
\hline \multirow[b]{2}{*}{$\begin{array}{c}e_{i} \\
(\mathrm{~m})\end{array}$} & \multirow[b]{2}{*}{$\begin{array}{c}r_{X i}(\mathrm{~m}) \\
\left(R_{X i}\right)\end{array}$} & \multirow[b]{2}{*}{ Response quantity } & \multirow[b]{2}{*}{$\begin{array}{l}\text { Original } \\
\text { model }\end{array}$} & \multicolumn{4}{|c|}{ Two-mass reduced model } \\
\hline & & & & $\begin{array}{c}\text { Reduced } \\
\text { earthquake } \\
\text { input }\end{array}$ & $\begin{array}{l}\text { Error } \\
(\%)\end{array}$ & $\begin{array}{c}\text { Simple } \\
\text { earthquake } \\
\text { input }\end{array}$ & $\begin{array}{l}\text { Error } \\
(\%)\end{array}$ \\
\hline \multirow{12}{*}{3.40} & \multirow{4}{*}{$\begin{array}{l}34.0 \\
(0.1)\end{array}$} & $\begin{array}{l}\text { Disp. of center of } \\
\text { mass (mm) }\end{array}$ & 238 & 232 & -2.59 & 201 & -15.3 \\
\hline & & $\begin{array}{l}\text { Angle of rotation } \\
\qquad\left(\times 10^{-3} \mathrm{rad}\right)\end{array}$ & 1.07 & 1.03 & -4.46 & 0.89 & -17.1 \\
\hline & & $\begin{array}{c}\text { Positive column } \\
\text { disp. (mm) }\end{array}$ & 222 & 217 & -2.60 & 188 & -15.4 \\
\hline & & $\begin{array}{l}\text { Negative column } \\
\text { disp. (mm) }\end{array}$ & 256 & 247 & -3.53 & 215 & -16.2 \\
\hline & \multirow{4}{*}{$\begin{array}{l}17.0 \\
(0.2)\end{array}$} & $\begin{array}{c}\text { Disp. of center of } \\
\text { mass }(\mathrm{mm})\end{array}$ & 161 & 157 & -2.29 & 137 & -15.1 \\
\hline & & $\begin{array}{c}\text { Angle of rotation } \\
\left(\times 10^{-3} \mathrm{rad}\right)\end{array}$ & 10.5 & 10.0 & -4.87 & 8.67 & -17.5 \\
\hline & & $\begin{array}{c}\text { Positive column } \\
\text { disp. (mm) }\end{array}$ & 207 & 199 & -3.68 & 173 & -16.4 \\
\hline & & $\begin{array}{l}\text { Negative column } \\
\text { disp. (mm) }\end{array}$ & 307 & 289 & -5.88 & 250 & -18.5 \\
\hline & \multirow{4}{*}{$\begin{array}{l}11.3 \\
(0.3)\end{array}$} & $\begin{array}{c}\text { Disp. of center of } \\
\text { mass (mm) }\end{array}$ & 202 & 190 & -6.04 & 164 & -18.6 \\
\hline & & $\begin{array}{l}\text { Angle of rotation } \\
\qquad\left(\times 10^{-3} \mathrm{rad}\right)\end{array}$ & 5.31 & 4.86 & -8.39 & 4.20 & -20.8 \\
\hline & & $\begin{array}{c}\text { Positive column } \\
\text { disp. (mm) }\end{array}$ & 278 & 258 & -7.21 & 224 & -19.7 \\
\hline & & $\begin{array}{l}\text { Negative column } \\
\text { disp. (mm) }\end{array}$ & 137 & 130 & -5.40 & 112 & -18.1 \\
\hline
\end{tabular}


Table 8 Comparison of various responses among the ten-story original model, the one-mass reduced model under reduced earthquake input and the one-mass reduced model under simple earthquake input for El Centro NS 1940

\begin{tabular}{|c|c|c|c|c|c|}
\hline \multirow[b]{2}{*}{ Response quantity } & \multirow[b]{2}{*}{$\begin{array}{c}\text { Original } \\
\text { model }\end{array}$} & \multicolumn{4}{|c|}{ One-mass reduced model } \\
\hline & & $\begin{array}{c}\text { Reduced } \\
\text { earthquake } \\
\text { input }\end{array}$ & $\begin{array}{c}\text { Error } \\
(\%)\end{array}$ & $\begin{array}{c}\text { Simple } \\
\text { earthquake } \\
\text { input }\end{array}$ & $\begin{array}{l}\text { Error } \\
(\%)\end{array}$ \\
\hline $\begin{array}{l}\text { Disp. of center of mass } \\
\text { (mm) }\end{array}$ & 91.9 & 83.7 & -8.89 & 62.6 & -31.9 \\
\hline $\begin{array}{l}\text { Angle of rotation } \\
\left(\times 10^{-3} \mathrm{rad}\right)\end{array}$ & 5.26 & 4.70 & -10.5 & 3.52 & -33.1 \\
\hline $\begin{array}{l}\text { Positive column disp. } \\
(\mathrm{mm})\end{array}$ & 132 & 119 & -9.83 & 89.1 & -32.6 \\
\hline $\begin{array}{l}\text { Negative column disp. } \\
\text { (mm) }\end{array}$ & 148 & 131 & -11.7 & 97.7 & -34.0 \\
\hline
\end{tabular}




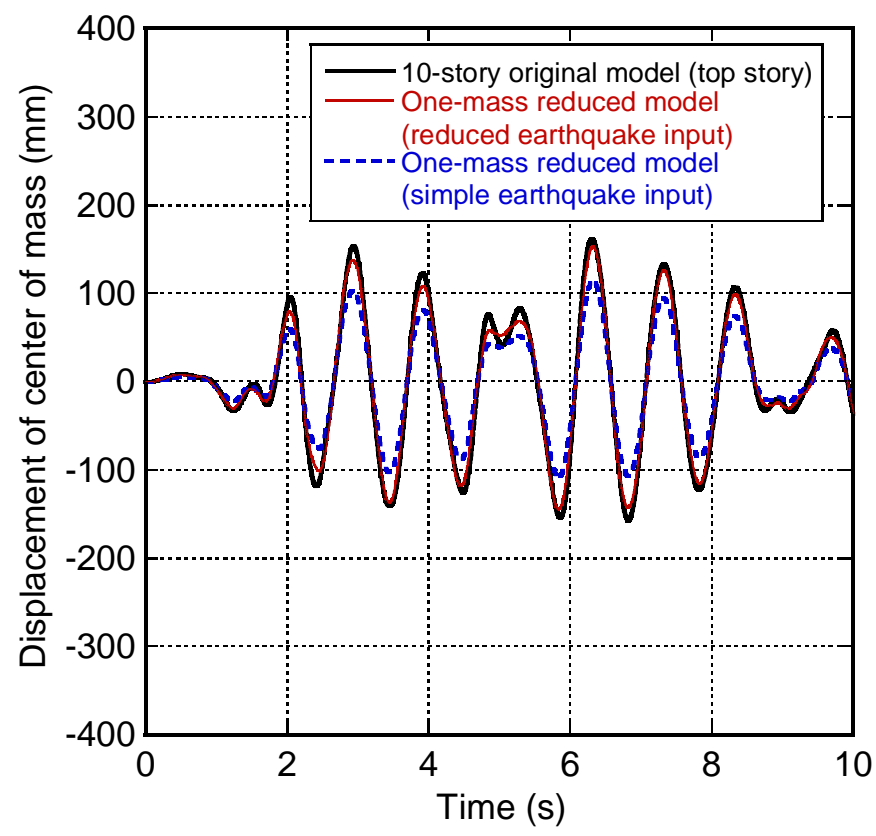

Fig.6 Comparison of $x$-directional displacements of center of mass among ten-story original model, one-mass reduced model under reduced earthquake input and one-mass reduced model under simple earthquake input (El Centro NS 1940)

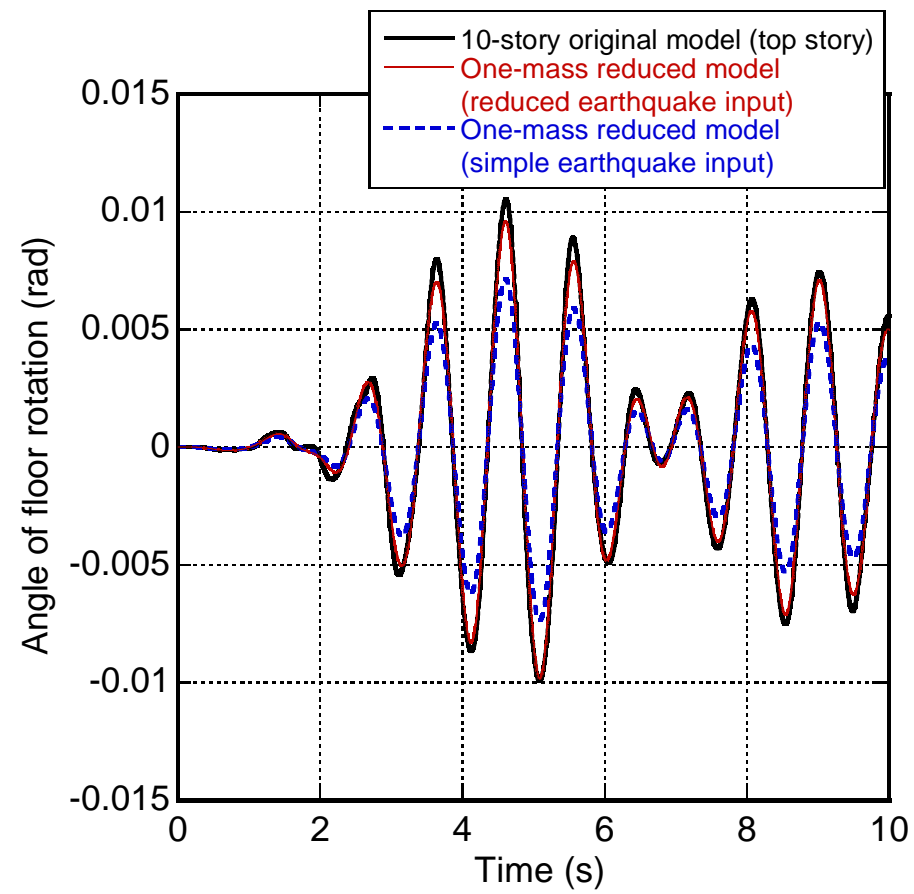

Fig.7 Comparison of angle of floor rotation among ten-story original model, one-mass reduced model under reduced earthquake input and one-mass reduced model under simple earthquake input (El Centro NS 1940) 


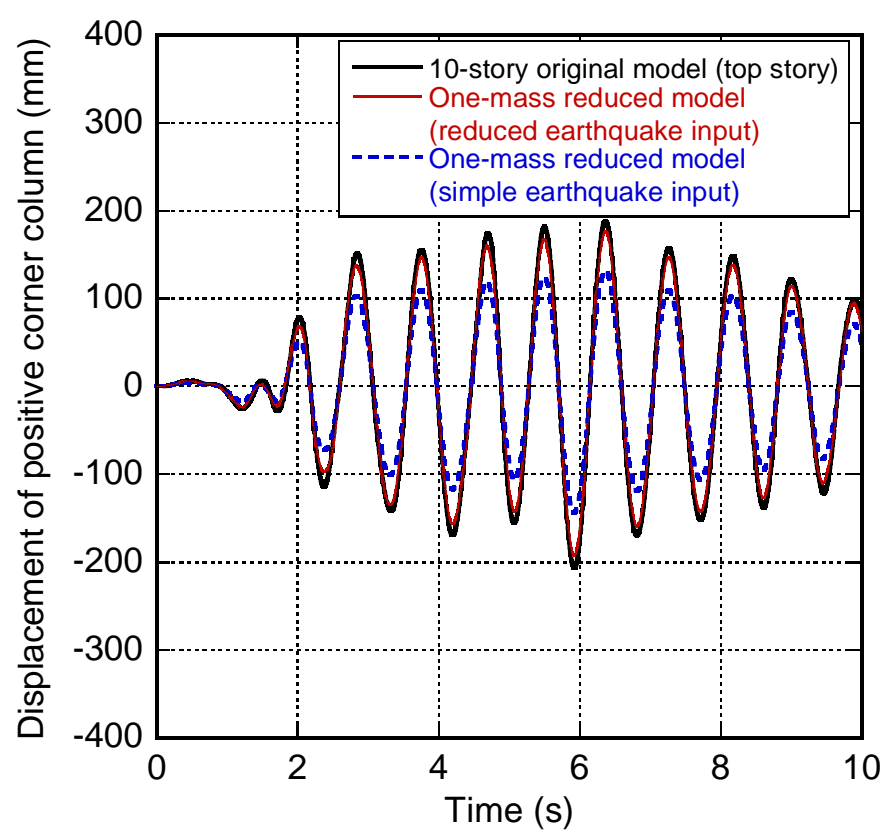

Fig.8 Comparison of $x$-directional displacements of positive corner column (see Fig.1(b)) among ten-story original model, one-mass reduced model under reduced earthquake input and one-mass reduced model under simple earthquake input (El Centro NS 1940)

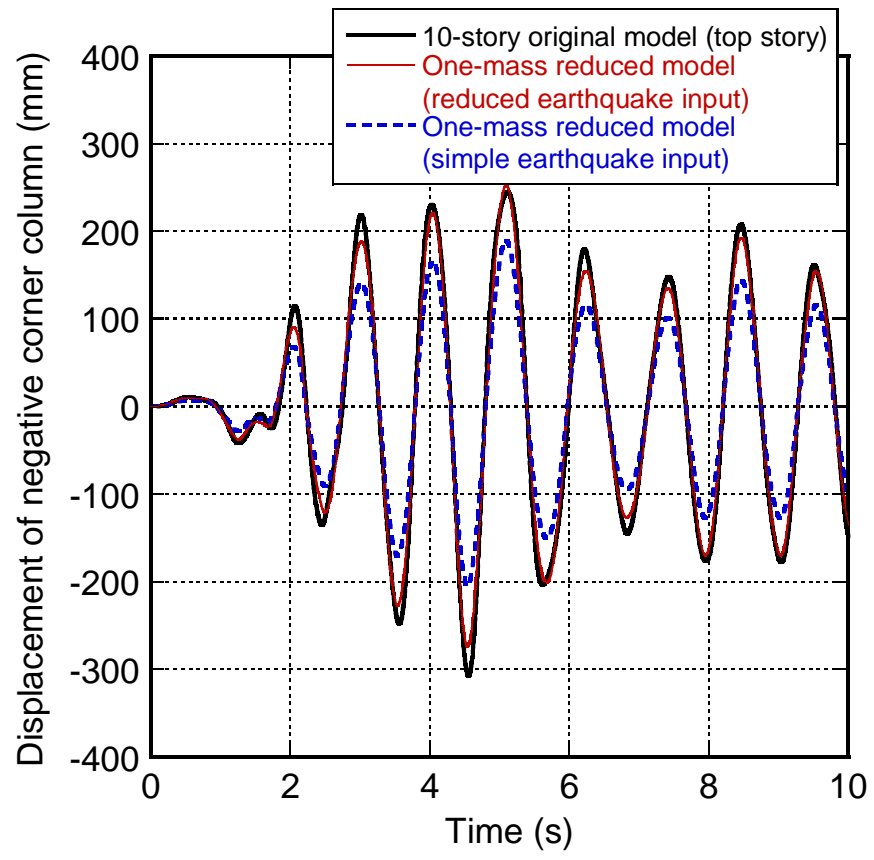

Fig.9 Comparison of $x$-directional displacements of negative corner column (see Fig.1(b)) among ten-story original model, one-mass reduced model under reduced earthquake input and one-mass reduced model under simple earthquake input (El Centro NS 1940) 


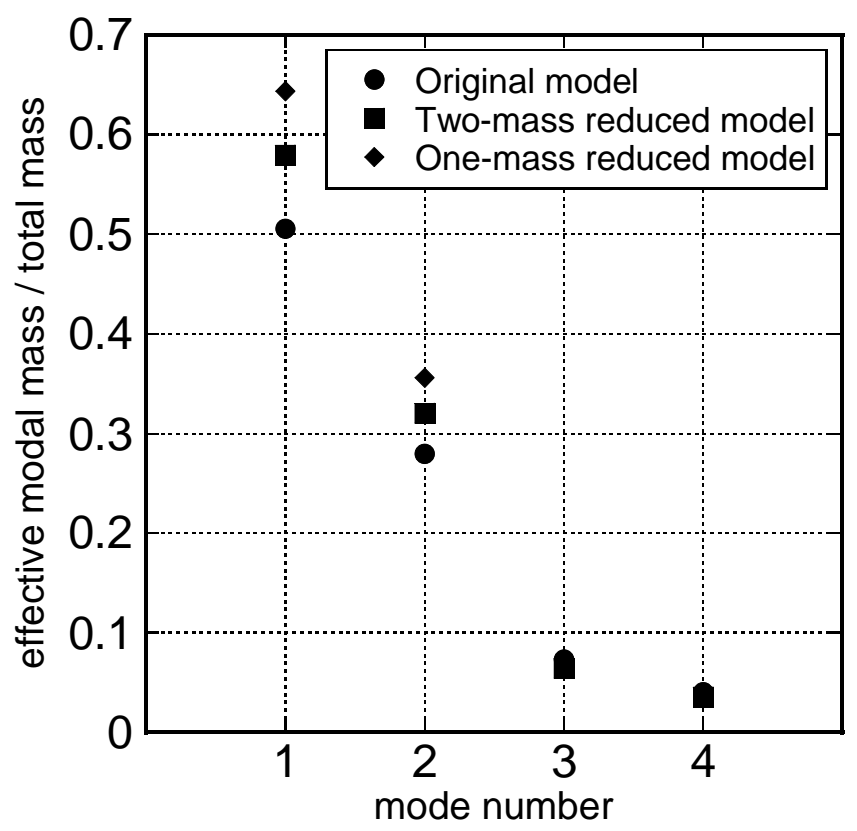

Fig.10 Effective modal masses divided by the total mass of the original model
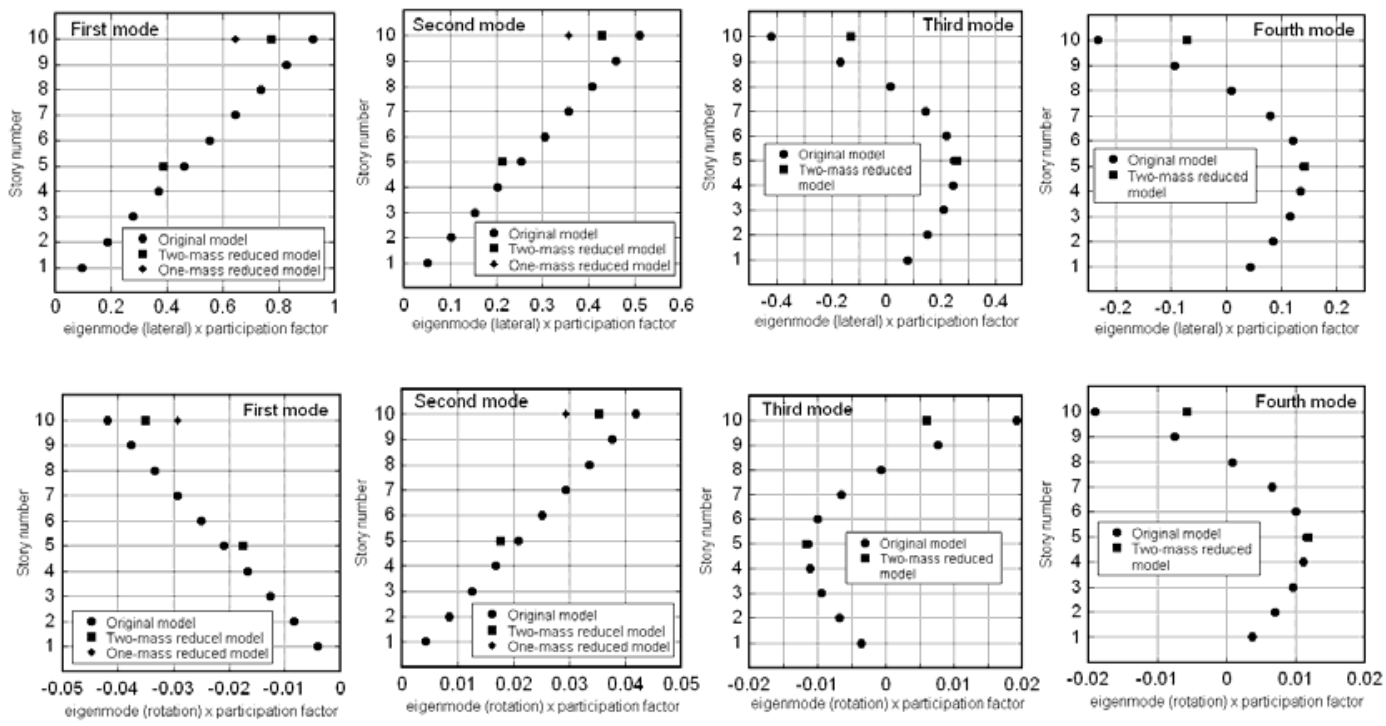

Fig.11 Eigenmodes multiplied by modal participation factors (original model, two-mass reduced model, one-mass reduced model) 


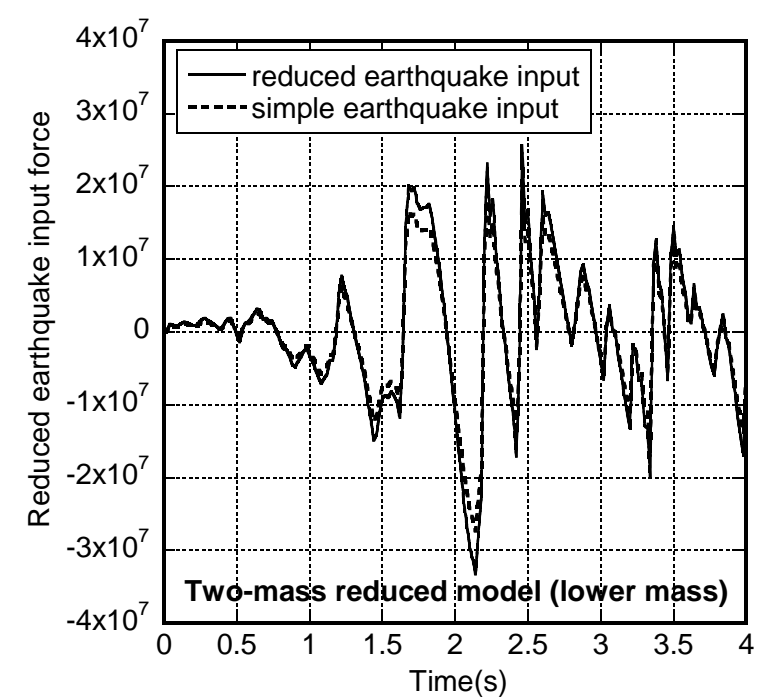

(a)

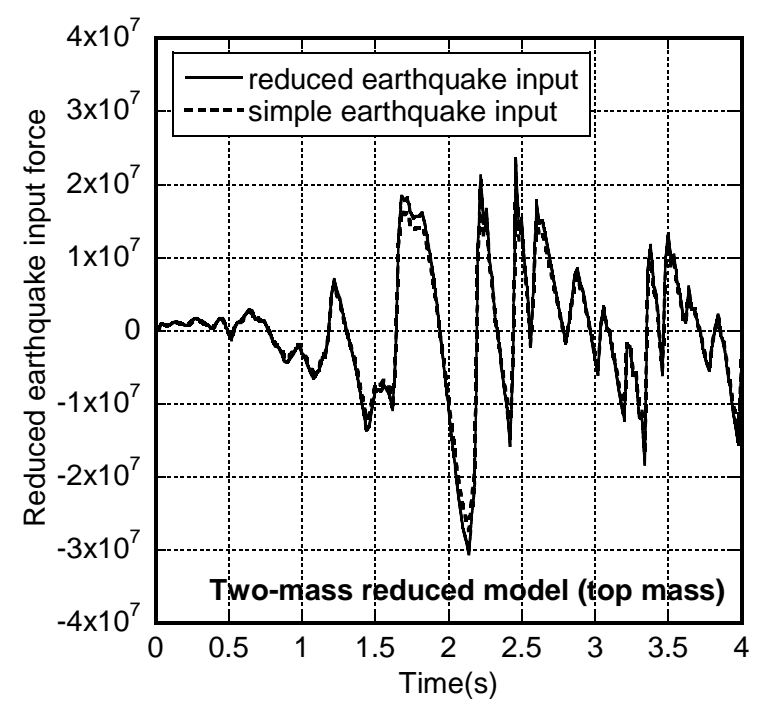

(b)

Fig.12 Reduced earthquake input and simple earthquake input to two-mass reduced model under El Centro NS 1940, (a) lower mass, (b) top mass 


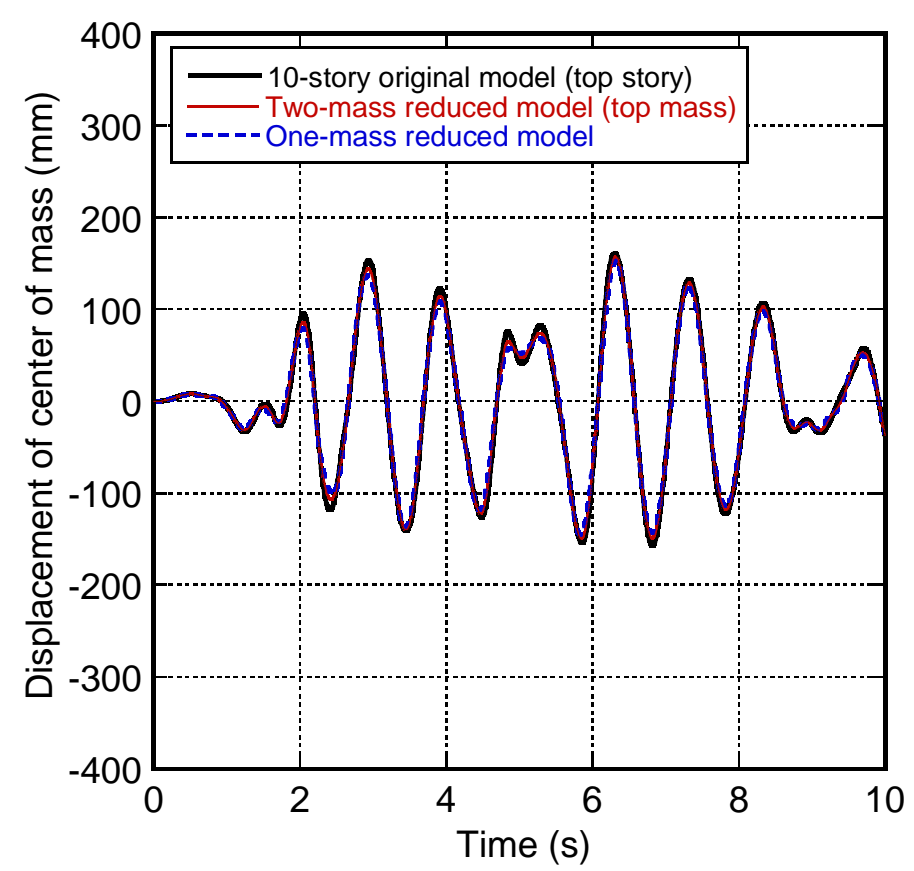

Fig.13 Comparison of $x$-directional displacements of center of mass among ten-story original model, two-mass reduced model under reduced earthquake input and one-mass reduced model under reduced earthquake input (El Centro NS 1940)

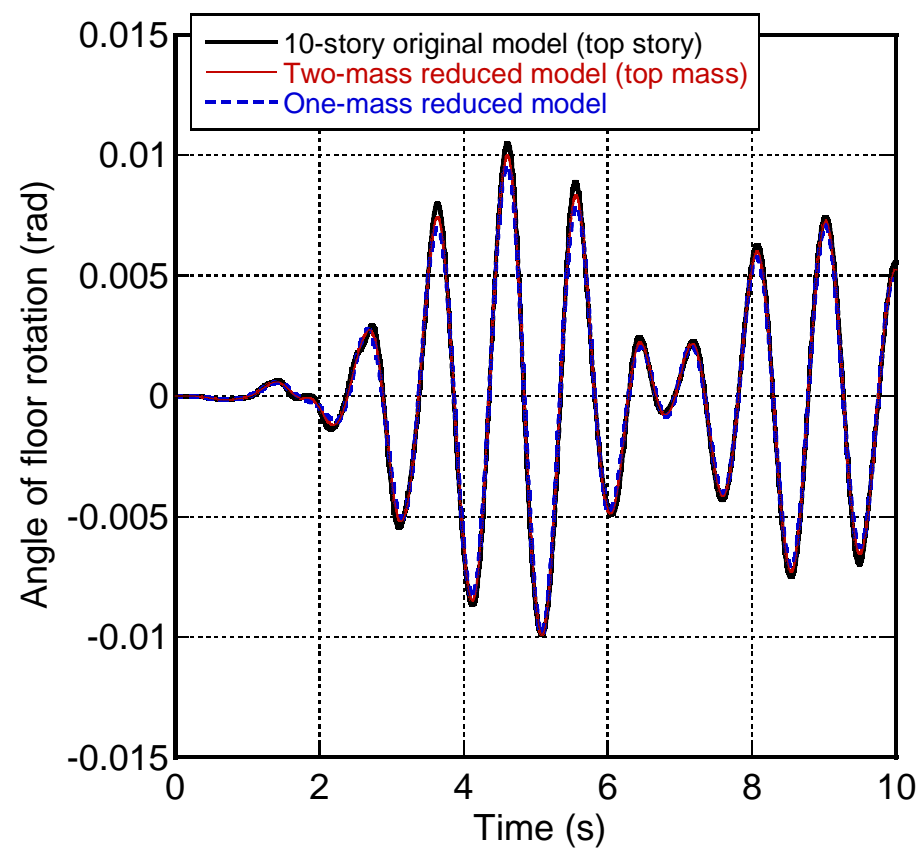

Fig.14 Comparison of angle of floor rotation among ten-story original model, two-mass reduced model under reduced earthquake input and one-mass reduced model under reduced earthquake input (El Centro NS 1940) 


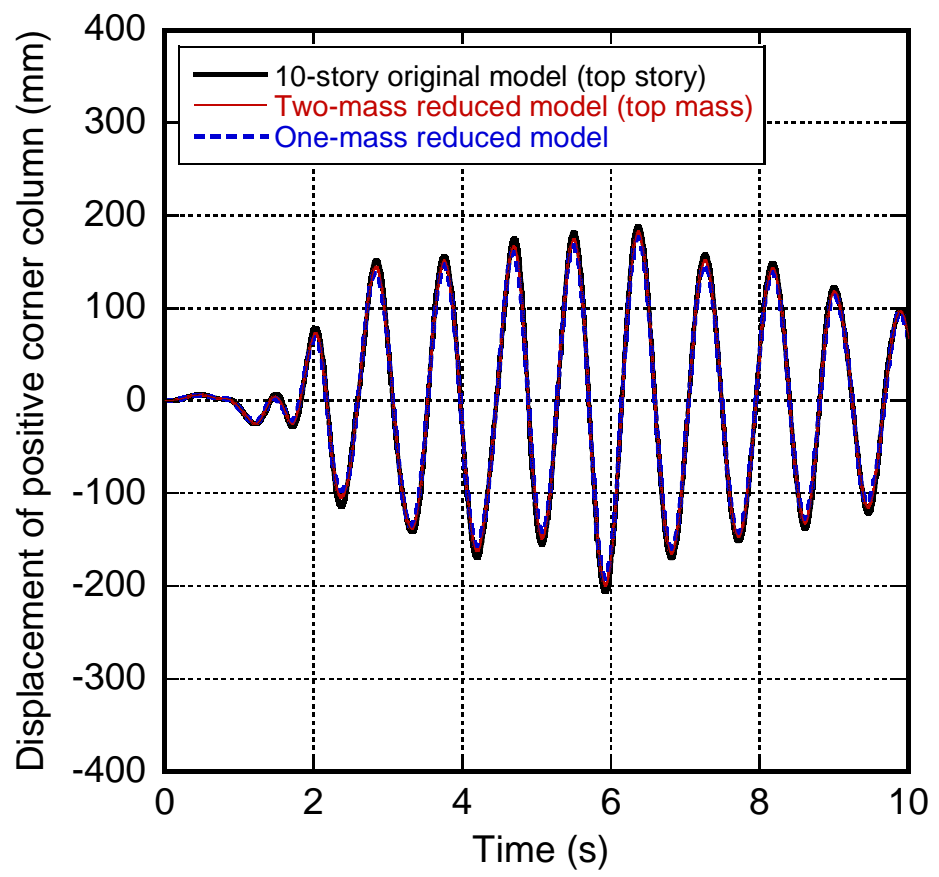

Fig.15 Comparison of $x$-directional displacements of positive corner column (see Fig.1(b)) among ten-story original model, two-mass reduced model under reduced earthquake input and one-mass reduced model under reduced earthquake input

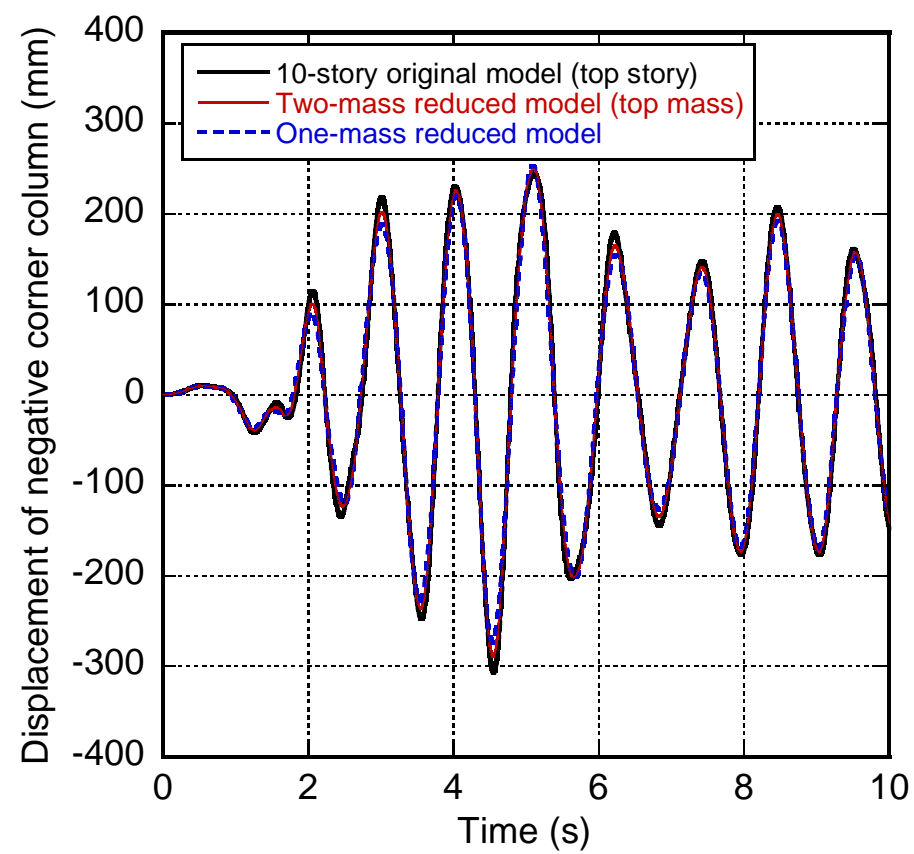

Fig.16 Comparison of $x$-directional displacements of negative corner column (see Fig.1(b)) among ten-story original model, two-mass reduced model under reduced earthquake input and one-mass reduced model under reduced earthquake input 


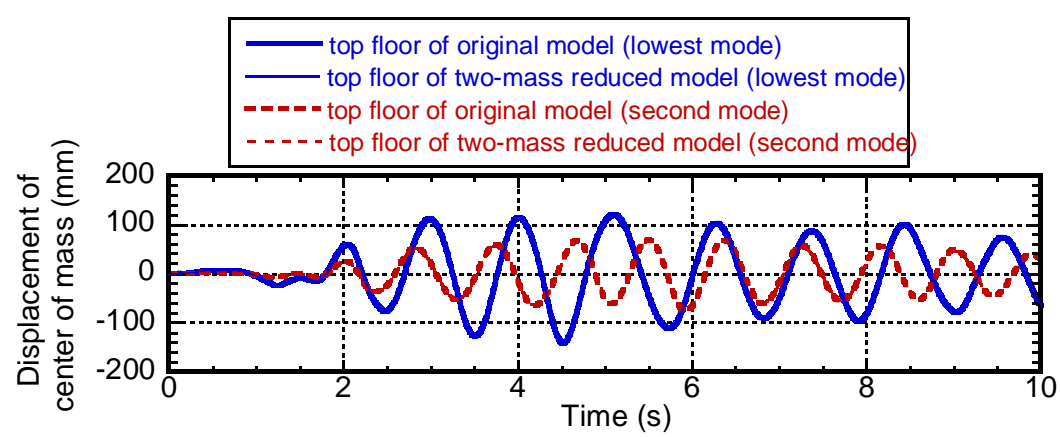

(a)

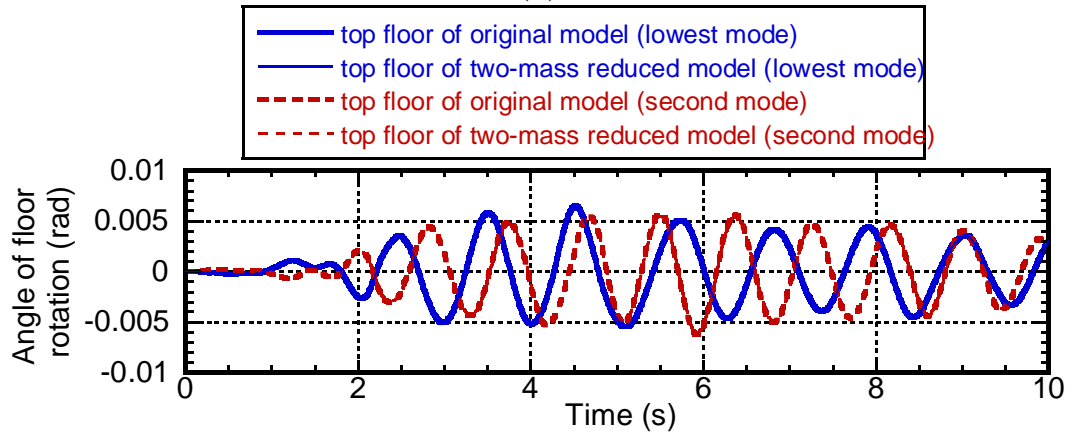

(b)

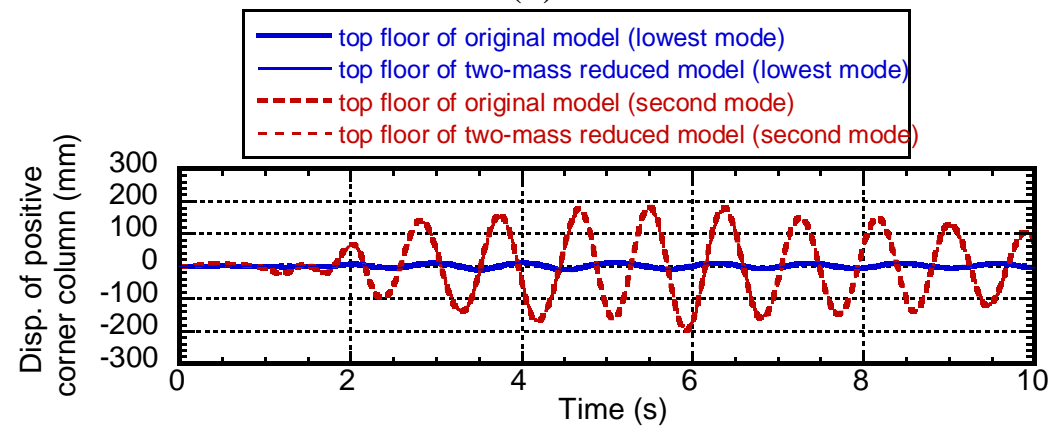

(c)

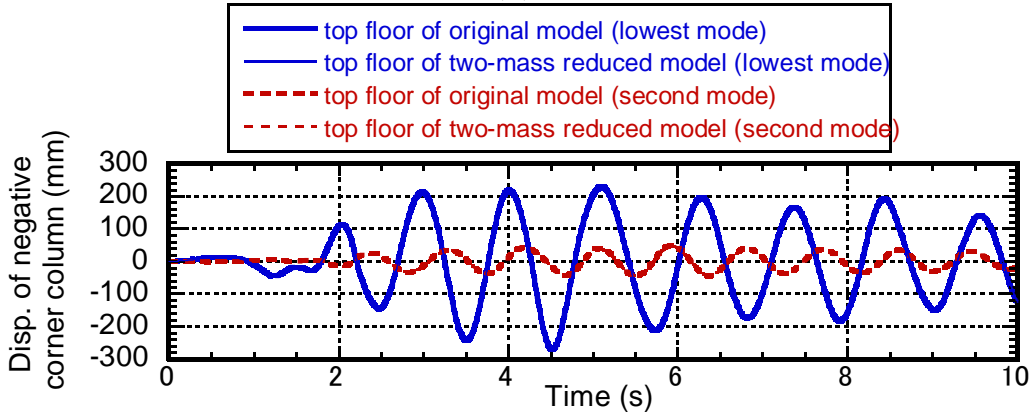

(d)

Fig.17 Comparison of modal responses between the ten-story original model and the twomass reduced model under reduced earthquake input for El Centro NS 1940

(a) Top-floor $x$-directional displacements of center of mass in the lowest two modal responses

(b) Angles of top-floor rotation in the lowest two modal responses

(c) $x$-directional displacement of top-story positive corner column (see Fig.1(b)) in the lowest two modal responses

(d) $x$-directional displacement of top-story negative corner column (see Fig.1(b)) in the lowest two modal responses 